\title{
A Knowledge Reuse Method for Product Design-knowledge Component
}

\author{
Duanwu YAN* \\ Department of Information Management \\ School of Economics and Management, NJUST \\ Nanjing, China \\ E-mail: yanwu_nju@163.com \\ +* Corresponding author
}

\author{
Ning JU \\ Department of Information Management \\ School of Economics and Management, NJUST \\ Nanjing, China \\ E-mail: ningxuantang@163.com
}

\author{
Kun CHEN \\ Department of Information Management \\ School of Economics and Management, NJUST \\ Nanjing, China \\ E-mail: 240910855@qq.com
}

\begin{abstract}
In order to promote the reuse of product design knowledge in product design and improve the efficiency of product design, the paper analyzes the structure of knowledge components, proposes the framework of product design system based on knowledge component, and studies the design and implementation of knowledge component combined with computer component technology. The barrel product is selected as the research object, of which the knowledge components are built. Then the paper designs and develops the design system based on knowledge component of the barrel. It proves the method based on knowledge component can effectively realize the reuse of product design knowledge. However, the developed knowledge components have certain limitations, which are only applicable to the same products or similar products. The generality of the knowledge components, the portability of the system and the migration of knowledge still need to be further verified.
\end{abstract}

Keywords-knowledge component; product design; knowledge reuse; component technology

\section{INTRODUCTION}

Product design is a complex and iterative process. With the development of computer technology, it presents the development trend of rapidness, personalization and better educated. Researches show that about $40 \%-50 \%$ parts of a new product in product design can be find from existing product parts library to achieve the same function, and 30\%$40 \%$ parts only need minor improvements in the existing parts. Only 10-20\% parts are required to be designed from scratch, but these redesigned parts only show the difference on the structure and shape with existing parts. Analyzed from function, principle and other high-level information of the product, they are still a reuse of existing design knowledge [1-3].

The research of product design knowledge reuse includes three aspects: knowledge acquisition, knowledge representation and knowledge utilization. Knowledge acquisition studies how to get all kinds of design knowledge in the process of product design. Knowledge representation studies how to store and represent the acquired design knowledge in a structured or unstructured manner. Knowledge utilization studies how to make the design knowledge serve the design process effectively to improve the design efficiency and quality. In the aspect of knowledge acquisition, domestic and foreign scholars have proposed knowledge acquisition methods based on rules, innovation algorithm, knowledge mining, artificial neural network, design process model, knowledge modeling and knowledge mapping [4-12]. In the aspect of knowledge representation, scholars have put forward knowledge representation methods, such as production rule, semantic network, Petri net model, Bayesian network, neural network and so on [13-16]. Knowledge utilization is the final goal of knowledge reuse. Although some scholars have put forward rule-based and case-based knowledge reasoning, a lot of design knowledge is still under "tube without" state. In order to improve the reuse of design knowledge, this paper studies the application of knowledge component in product design.

The component thought of computer software has an inherent fit with the knowledge reuse of product design. The knowledge component in this paper combines the product knowledge with design process closely to make the design knowledge serve the process of design, which can reduce the time for designers to collect experience in product design, so as to reduce time cost, reduce errors and improve design efficiency and reliability of design quality.

\section{KnOWLedge Reuse of Product Design KNOWLEDGE BASED ON KNOWLEDGE COMPONENT}

Knowledge component is the product of the combination of component technology and knowledge reuse in computer software. It can be regarded as a knowledge unit with certain functions. In the field of product design, knowledge component can package a variety of different types of knowledge (data, rules, templates, standards, examples, processes, etc.) in a structured way, which is acquired in 
design process. Under driver control, it can accept parameter, perform actions and return results in an automated or semi automated manner [17].

\section{A. Knowledge Reuse Model Based on Knowledge Component}

According to the auxiliary way of knowledge reuse for designers, some scholars divide knowledge reuse models of product design into for types: the reference knowledge reuse mode, the guidance knowledge reuse model, the automatic knowledge reuse model and the assistance knowledge reuse model [18].

The reference knowledge reuse mode provides designers with a way to search and browse design knowledge so that designers can quickly obtain the design knowledge related to the current design tasks. It usually adopts the methods of active push and passive search to provide better knowledge support for designers to make decisions. The guidance knowledge reuse model is a way to guide designers to reuse the product design knowledge. In this model, the design knowledge is mainly the design flow. The automatic knowledge reuse model means that designers can directly use the existing design model and design algorithm, which can liberate designers from tedious repetitive work and lighten the burden of work. The assistance knowledge reuse model provides information of domain experts when designers face problems that cannot be solved because the knowledge base cannot contain all design knowledge and some design knowledge is too complicated.

In this paper, the knowledge reuse based on knowledge component is combined with reference mode and automatic mode. The knowledge components not only package the design function, but also package the related design knowledge. When the knowledge components are used to design product, the design knowledge pushed by component will be received to help designers make the decision. As a component with a certain function, the knowledge component can be repeated called by the design system. Moreover, the knowledge component can also call external algorithms, tools and so on.

\section{B. Execution Process of Knowledge Components}

As shown in Fig. 1, the product design task accesses the control interface of knowledge component and activates the knowledge component in a semi-automatic way.

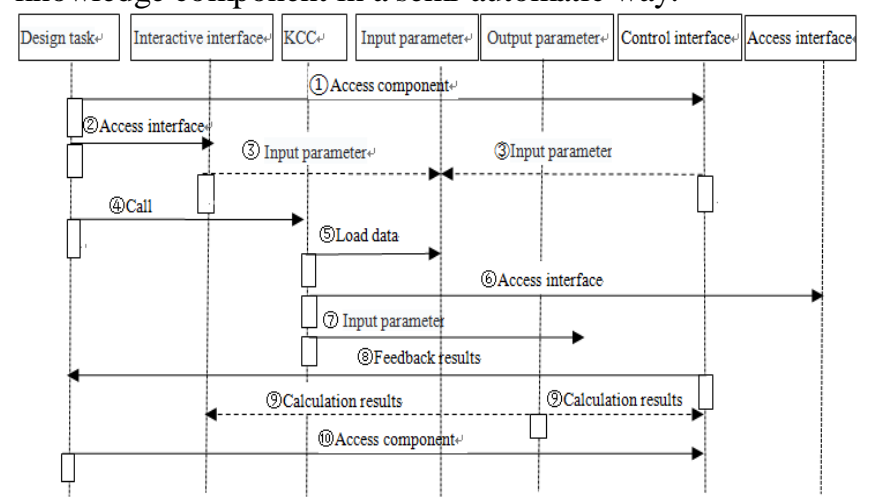

Figure 1. Execution process of knowledge components
Then the designers input the parameters of knowledge component through the man-machine interactive interface. The knowledge component accepts user input and runs the knowledge component core (KCC). KCC calls the Interactive interface to access the third party software, knowledge base, and other knowledge components when execute function, and outputs results. Under the premise of feeding back the execution results, KCC returns the output parameters to the man-machine interactive interface or access the output data through the control interface.

\section{Product Design System Based on Knowledge Component}

The design system packages the design knowledge into knowledge component in a structured form, and then calls the knowledge component to design product. The interface layer is an interactive window between designers and the system. The system receives design input from the designer and drives the knowledge components of the business layer to perform input validation. If the verification is unsuccessful, the result is returned to the interface layer, which reminds the designer to modify the design input. If the validation is successful, the system continues to execute function and generate results. Then the generated design results are returned as output to the interface layer. In the process of executing functions, knowledge components need to frequently access the knowledge layer to obtain design knowledge and write the design results into the knowledge base, as shown in Fig. 2:

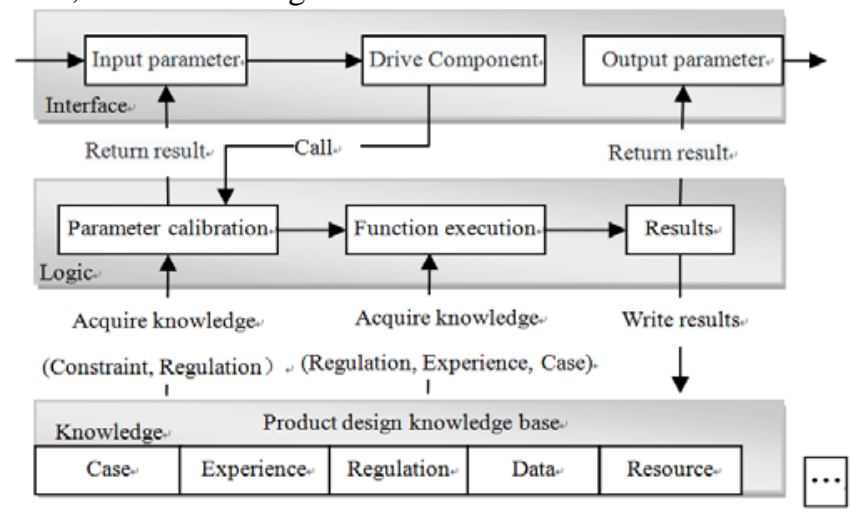

Figure 2. Product design system based on knowledge component

\section{Structure ANAlysis AND DESign OF KNOWLEDGE COMPONENT}

\section{A. Structure Analysis of Knowledge Component}

1) The construction principle of knowledge component

In order to determine the structure of knowledge components, it is necessary to define the principles of building knowledge components. How to design and obtain reusable knowledge components is the most important problem for the system developers to consider. In general, the building and development of knowledge components should focus on the following aspects: 
a) Encapsulation of knowledge components: Component developers can define their own events in the knowledge component, and users do not need to know the complex internal details.

b) Appropriate knowledge component granularity: On the basis of analyzing the function and realization mechanism, developers should analyze and design the design flow to be knowledge components with appropriate granularity so as to maintain the independence of knowledge component function and structure, which can effectively avoid bloated knowledge components, improve the knowledge component execution efficiency, and reduce the complexity of its realization.

c) Reuse of knowledge components: Before the design and development of the system, developers can select the knowledge components meeting the functional requirements from the domain knowledge component library to assemble the application system, which can speed up the development of system and improve the efficiency of system development. The newly developed knowledge components can also be used in the following new product design.

\section{2) The classification of knowledge components}

The types of knowledge components vary according to the different requirements of system functions. Generally speaking, there are three types: interface class, activity class and data management class. According to the functional requirements, this paper abstracts the function modules of the design system and packages them into general knowledge components. Eventually we divide knowledge components into knowledge access knowledge component, business logic knowledge component and interface display knowledge component. Each kind of knowledge component is composed of a variety of functional components. We design and realize the knowledge components according to the characteristics of knowledge components and the development technology. The classification of knowledge components are shown in Table I:

TABLE I. THE CLASSIFICATION OF KNOWLEDGE COMPONENTS

\begin{tabular}{|l|l|l|}
\hline Classification & $\begin{array}{l}\text { Knowledge } \\
\text { component }\end{array}$ & Description \\
\hline $\begin{array}{l}\text { Knowledge } \\
\text { access } \\
\text { knowledge } \\
\text { component }\end{array}$ & $\begin{array}{l}\text { Database } \\
\text { Access }\end{array}$ & $\begin{array}{l}\text { Database access is the basic type of } \\
\text { knowledge components, involving data } \\
\text { storage, retrieval and update. }\end{array}$ \\
\hline $\begin{array}{l}\text { Business } \\
\text { logic } \\
\text { knowledge } \\
\text { component }\end{array}$ & $\begin{array}{l}\text { Data } \\
\text { calculation }\end{array}$ & $\begin{array}{l}\text { Accept input parameters, calculate data, } \\
\text { such as parameter calculation, design } \\
\text { optimization, etc.. }\end{array}$ \\
\cline { 2 - 3 } & $\begin{array}{l}\text { Parameter } \\
\text { constraint }\end{array}$ & $\begin{array}{l}\text { Check and restrict the input parameters } \\
\text { and design results generated in real-time }\end{array}$ \\
\hline $\begin{array}{l}\text { Interface } \\
\text { display } \\
\text { knowledge } \\
\text { component }\end{array}$ & $\begin{array}{l}\text { Retrieval } \\
\text { interface }\end{array}$ & $\begin{array}{l}\text { Retrieve design knowledge, including } \\
\text { case retrieval, knowledge resource } \\
\text { retrieval and so on. }\end{array}$ \\
\cline { 2 - 3 } & $\begin{array}{l}\text { Parameter } \\
\text { input }\end{array}$ & $\begin{array}{l}\text { According to the design task, the designer } \\
\text { fills in the parameters needed for the } \\
\text { product design }\end{array}$ \\
\cline { 2 - 3 } & $\begin{array}{l}\text { Result } \\
\text { output }\end{array}$ & $\begin{array}{l}\text { The results output component is a carrier } \\
\text { which can display the result of the } \\
\text { operation, including chart output, data } \\
\text { output and file output. }\end{array}$ \\
\hline
\end{tabular}

\section{3) The structure of knowledge component}

Knowledge component structure can be abstracted as: $\mathrm{KC}=\{\mathrm{KCC}, \mathrm{DI}, \mathrm{UII}, \mathrm{AI}, \mathrm{CI}\}$. Where: KCC (Knowledge Component Core) is the core component of knowledge representation, which represents knowledge content or encapsulation knowledge solver and is the core tool to complete user design request. It is activated according to the start command of user interaction interface. Through the analysis of knowledge unit, KCC associates the control rules and the experience value with the data input interface, intelligently judge the mutual restriction relation between the input parameter range and the input parameter, and feedback executing information to the user interaction interface. It is also used to provide the output file to the output data interface. DI (Data Interface) represents data interface, including input data interface and output data interface. Input data interface obtains data and passes it to KCC for data processing. Output data interface obtains KCC processing data and return it to the user interaction interface. UII (User Interaction Interface) represents the user interaction interface, which is the human-computer interaction interface for users to set up, operate and describe the relevant attribute information. The user interaction interface is connected to KCC, which is used to send the start command to KCC. AI (Access Interface) represents access interface, which is used by knowledge components to invoke or access third party software, tools, and other knowledge components. CI (Control Interface) represents the control interface, through which the external system calls knowledge components and drives knowledge component run. Through the encapsulation of knowledge components, the formalization of analysis and design knowledge process is realized so that the knowledge analysis and design process can be accumulated, shared and reused. The knowledge component structure is shown in Fig. 3:

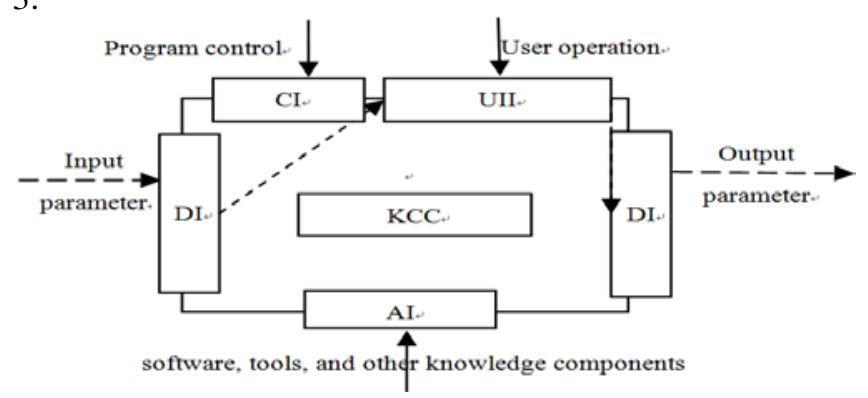

Figure 3. The structure of knowledge component

\section{B. Design and Implementation of Knowledge Component}

Packaging the function of knowledge components into components rather than calling external programs can reduce the running time. And the knowledge components can be reused, which can reduce the burden on developers, improve the system development efficiency and reduce system maintenance difficulty.

1) Design and implementation of knowledge access knowledge component

The function of knowledge access knowledge component is to control the data flow with database, including the 
realization of the product design system to obtain data from the database and write data to the database. The function of knowledge access knowledge component includes database connection configuration, database query, database insert, delete and update operation. In product design, database access is a common operation. Before the database operation, system needs to connect to the database at first. Through establishing the database configuration connection component, the system packages the database connection operation, which saves the system developers to repeat the tedious coding and saves development time.

Different functions have different input parameters and output results when accessing the database. In order to realize the reuse of software to the greatest extent, the knowledge access knowledge component studied in this paper uses the SQL statement to pass parameters to realize the data query, insert, delete and update operation and then return the operation results. The results include two cases of success and failure. Among them, the database search results are returned by the search result set, and the search method parameters include SQL statements, fields and other parameters. Different application systems get the database access interface through the access method of knowledge components. And the function methods of knowledge access knowledge components are shown in Table II:

TABLE II. The FUnCTION METHOD OF KNOWLEDGE ACCESS KNOWLEDGE COMPONENTS

\begin{tabular}{|c|c|c|}
\hline $\begin{array}{c}\text { Access } \\
\text { type }\end{array}$ & Function method & Description \\
\hline Query & 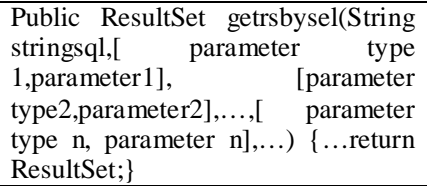 & $\begin{array}{l}\text { Return the result set } \\
\text { based on the stringsql } \\
\text { SQL statement. }\end{array}$ \\
\hline Insert & 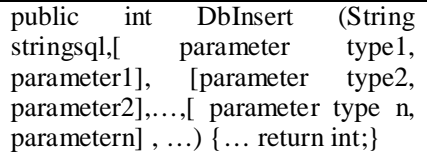 & $\begin{array}{l}\text { Perform database } \\
\text { insert operation and } \\
\text { return the in value } \\
\text { based on the results of } \\
\text { the execution. }\end{array}$ \\
\hline Delete & 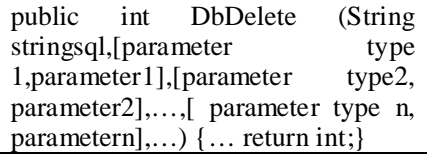 & $\begin{array}{l}\text { Perform database } \\
\text { delete operation and } \\
\text { return the int value } \\
\text { based on the results of } \\
\text { the execution. }\end{array}$ \\
\hline Update & $\begin{array}{l}\text { public int DbUpdate } \begin{array}{r}\text { (String } \\
\text { stringsql,[parameter }\end{array} \\
\text { 1,parameter1], [parameter type 2, } \\
\text { parameter2],..,[ parameter type n, } \\
\text { parameter } n], \ldots) \text { \{... return int; }\}\end{array}$ & $\begin{array}{l}\text { Perform database } \\
\text { update operation and } \\
\text { return the int value } \\
\text { based on the results of } \\
\text { the execution. }\end{array}$ \\
\hline
\end{tabular}

\section{2) Design and implementation of business logic} knowledge component

The basic object of the business logic class knowledge component is the entity data acquired by knowledge access knowledge component or the user input of interface display knowledge component. The business logic process involves several interactions among basic objects and multiple interactions of knowledge access knowledge component. Therefore, in order to achieve a consistent object and a complete process, the business logic knowledge component must support transaction processing. The size of the business logic knowledge component is relatively large, so it involves multiple knowledge components. At the same time, it provides a unified method and interface to the interface display knowledge component, which can be reused in many applications.

TABLE III. ThE DATA CALCULATION DESCRIPTION FIELDS

\begin{tabular}{|l|l|}
\hline Description field & Description \\
\hline Name & $\begin{array}{l}\text { The name of the data unit, such as the formula } \\
\text { for calculating the theoretical strength }\end{array}$ \\
\hline Design part & $\begin{array}{l}\text { A design part the formula belongs to,such as a } \\
\text { tube part. }\end{array}$ \\
\hline Design activity & $\begin{array}{l}\text { A design activity the formula belongs to, such } \\
\text { as the calculation of the theoretical strength }\end{array}$ \\
\hline Data calculation formula & Content of formula \\
\hline Input parameter & $\begin{array}{l}\text { Input parameters for designing knowledge } \\
\text { components }\end{array}$ \\
\hline Output parameter & $\begin{array}{l}\text { Output parameters for designing knowledge } \\
\text { components }\end{array}$ \\
\hline Calculation principle & $\begin{array}{l}\text { Clarify the principle of data calculation } \\
\text { formula }\end{array}$ \\
\hline Calculation example & The actual sample solution of the formula \\
\hline Entry time & The entry time of data calculation formula \\
\hline Entry personnel & The entry personnel of data calculation formula \\
\hline
\end{tabular}

TABLE IV. Single Cylinder TuBe KNOWLEdge COMPONENT PROPERTY TABLE

\begin{tabular}{|c|c|c|}
\hline Step & $\begin{array}{c}\text { Component property } \\
\text { definition }\end{array}$ & Property description \\
\hline $\begin{array}{l}\text { Design } \\
\text { task }\end{array}$ & Strsjrwbh & Design task number \\
\hline $\begin{array}{l}\text { Case } \\
\text { retrieval }\end{array}$ & \begin{tabular}{l} 
Strypwljfs,strypkztqljfs, \\
strkj, \\
strdwzl,strcs,strzdty; \\
valueypwljfs, \\
\multicolumn{2}{c}{ valueypkztql } \\
jfs, valuekj, valuedwzl, \\
$\quad$ valuecs, \\
valuezdty, Vector \\
vectorinstance
\end{tabular} & $\begin{array}{l}\text { Connection way with breech, } \\
\text { connection way with breech leg, } \\
\text { caliber, projectile weight, } \\
\text { initial velocity, weight of each } \\
\text { parameter and case retrieval } \\
\text { result }\end{array}$ \\
\hline $\begin{array}{l}\text { Interior } \\
\text { ballistic } \\
\text { design } \\
\text { parameter }\end{array}$ & $\begin{array}{lr}\text { strYsmj, } & \text { strYsc, } \\
\text { strDwxcz, } & \text { strZyl, } \\
\text { strYsrj } & \end{array}$ & $\begin{array}{l}\text { Chamber area, chamber length, } \\
\text { projectile trip length, charge and } \\
\text { chamber volume }\end{array}$ \\
\hline $\begin{array}{l}\text { Bore } \\
\text { design } \\
\text { parameter }\end{array}$ & \begin{tabular}{lr} 
strYsbtc, & strLjzc, \\
strYzbc, & strTxc, \\
strDxbc, & strYsdbj, \\
strYsbbtmdbj, & \\
strLjzmdbj, & \\
strYzbmdbj, & \multicolumn{2}{c}{ strTxmdbj, }
\end{tabular} & $\begin{array}{l}\text { Chamber body length, cone } \\
\text { length, cylindrical connection } \\
\text { length, orientation of ministers, } \\
\text { ministers, rifling chamber } \\
\text { bottom radius, the chamber body } \\
\text { end radius, end radius of } \\
\text { cylinder, end radius of } \\
\text { connection, end radius of } \\
\text { connection }\end{array}$ \\
\hline $\begin{array}{l}\text { High and } \\
\text { low } \\
\text { temperatur } \\
\text { e pressure } \\
\text { curve }\end{array}$ & float[] l,float[] p,intlen & $\begin{array}{l}\text { Length array, pressure array, and } \\
\text { points }\end{array}$ \\
\hline $\begin{array}{l}\text { Theoretica } \\
1 \text { strength } \\
\text { calculation }\end{array}$ & $\begin{array}{l}\text { strysbaqxs,strtxbaqxs,str } \\
\text { pkbaqxs,float[] } \\
\text { qdl,float[] qdq,intlen }\end{array}$ & $\begin{array}{l}\text { Chamber safety factor, rifling } \\
\text { safety factor,muzzle safety } \\
\text { factor,length array, theoretical } \\
\text { strength and point }\end{array}$ \\
\hline $\begin{array}{l}\text { Theoretica } \\
\mathrm{l} \\
\text { appearanc } \\
\mathrm{e} \\
\text { calculation }\end{array}$ & $\begin{array}{l}\text { strzdtyz,strgcgh,strqdjx, } \\
\text { double[] gjd,double[] } \\
\text { nj,double[] qd, } \\
\text { double[] wj }\end{array}$ & $\begin{array}{l}\text { The maximum chamber } \\
\text { pressure, the ultimate strength of } \\
\text { steel Key point length array, } \\
\text { inner diameter array, intensity } \\
\text { value array and OD value array }\end{array}$ \\
\hline
\end{tabular}


According to the knowledge needs of each design activity in the process of product design, it collects knowledge resources related to design activities and combines them into the knowledge unit module corresponding to each design activity. The data calculation description fields are shown in Table III.

The paper takes the design of single cylinder tube as the research object. Properties of single cylinder tube component include single tube design task number, connection way with breech, connection way with breech leg, caliber, projectile weight, initial velocity, parameter weight, case retrieval results, chamber area, chamber length, bullet stroke length, charge and chamber volume etc. The input singer properties fields designed include instance retrieval properties, interior ballistic design parameters, bore design parameter, high and low temperature pressure data, the safety coefficient of the chamber, the safety coefficient of rifling, the safety coefficient of the muzzle and steel grades of the steel selected. Input forms include providing parameter input page, reading Txt, Excel and other documents, and reading database data. The output includes the results of the case retrieval, the display of the instance attributes, the table of high and low temperature pressure curves and the theoretical strength map, as shown in Table IV.

3) Design and implementation of interface display knowledge component

The interface is responsible for the dialogue between the system and the designer. It accepts and examines the designer input, and then passes the parameters to the business logic knowledge component for business processing. The processing results are returned to the user interface, which is convenient for users to view the design results and evaluate the design scheme. The interface display knowledge components include accepting design input, design output, automatic or semi-automatic execution and so on. The input component designed is used for the maintenance of the design object information and product monomer element settings. The designer fill in the parameters required for product design according to the design tasks and knowledge needs. The output component designed is a kind of carrier which can display the result of the operation, including chart output, data output and file output. Because of the different design languages, the processing modes and design methods of the interface display knowledge component are also different. This paper uses Swing to design and develop interface components. It designs knowledge components through the Swing intermediate component. Then it puts the intermediate knowledge component into the top-level component, and conducts interface display. The interface component display structure is shown in Fig. 4:

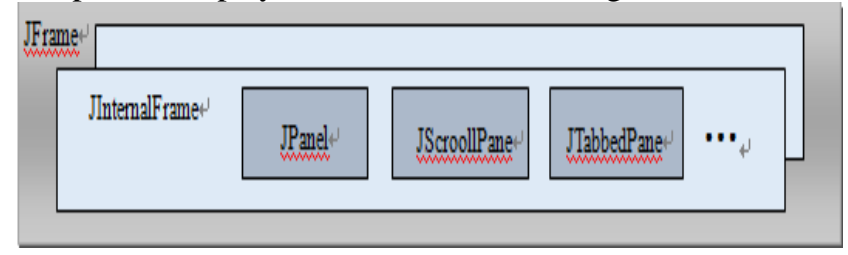

Figure 4. The interface component display structure
JFrame achieves sub function through the menu and menu click event pop up JInternalFrame. JInternalFrame fills JPanel, JScroollPane and JTabbedPane and other intermediate components. Among them, JInternalFrame, JPanel, JScroollPane, JTabbedPane and other intermediate components can define the reusable interface display knowledge components according to the contents.

\section{APPLICATION EXAMPLE OF KNOWLEDGE REUSE IN Product Design Based on KNowledge Component}

Taking the design of the single tube body part as an example, this paper studies the application of knowledge component in knowledge reuse of product design, then designs and develops three kinds of knowledge components according to the design process and design requirements. The knowledge access knowledge component is defined as DbAccess.java, and the design system realizes the database operation access through DbAccess.java. The business logic knowledge component is defined as MonblockDesign.java and packages the method of package design in each step. The interface display knowledge components includes InstanceShower.java, which shows pages of the retrieval instance display and the program design steps and the JnternalFrame pages for each application system, as shown in Fig. 5:

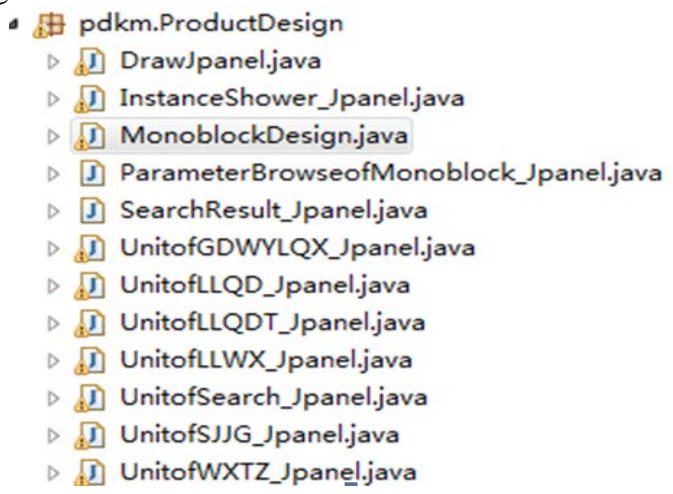

Figure 5. The development of interface display knowledge components

When the system is running, it first calls the interface display knowledge component to provide a window for the designer to interact with the design system, as shown in Fig. 6:

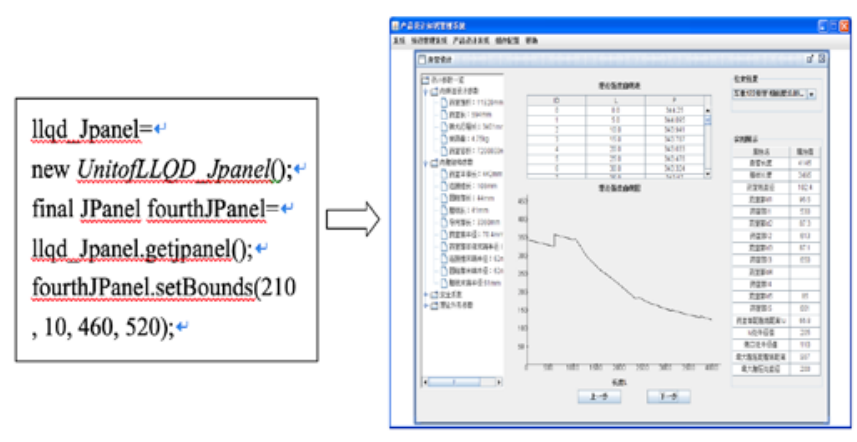

Figure 6. The interface of single tube design theoretical strength calculation 
Then the business logic knowledge component includes the method of the single cylinder tube design step. The system calls the MonblockDesign single cylinder tube knowledge component to realize the related functions:

publicvoid countsjrwbh() // Code the design task number according to certain principles;

public void instanceSearch() // Case retrieval based on search fields;

private double countInstancesim() // Calculate example similarity;

public void jsllqd() // Calculate single tube body strength curve;

public void llwx_jsgjd() // Calculate theoretical contour point value;

public void llwx_jsnjz() // Calculate theoretical inner diameter; value;

public void llwx_jsqdz() // Calculate theoretical strength

public void llwx_jswjz() // Calculate theoretical outer diameter;

public int commit() // Store single cylinder tube design examples into the database.

In the "case retrieval" function, the system can search and view the successful design cases through the selection and setting of the characteristic parameters and the parameter weights, which can provide decision basis for designers in design and is the embodiment of knowledge reuse in the reference model, as shown in Fig. 7:

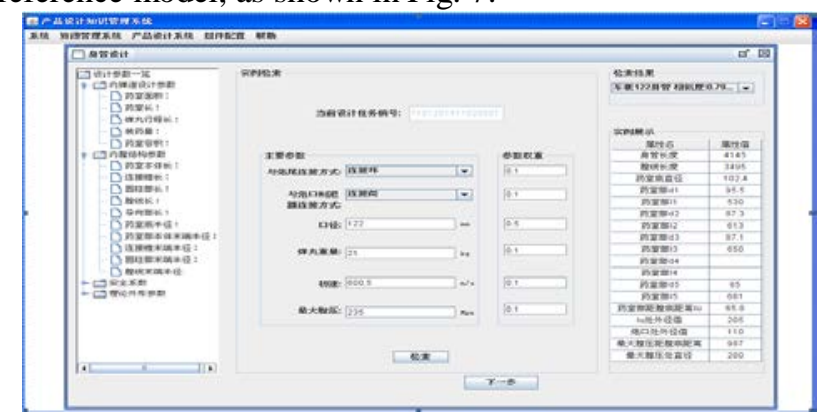

Figure 7. The retrieval interface of single tube design

\section{CONCLUSION}

In order to solve the problems that the reuse of product design knowledge is not enough in product design, the design knowledge in the product design system is difficult to reuse and transplant in the program, and the knowledge reuse cannot be effectively linked to software engineering, this paper studies the product design based on knowledge component and sums up the knowledge component encapsulation, suitable granularity as well as the construction principle of reusability. Through the design and realization of the body tube design system, it verifies the feasibility and effectiveness of the knowledge component structure and design implementation method. What's more, it solves the problem of transplant and reuse of product design system, which is convenient for designers to use, to realize the knowledge reuse of product design based on knowledge component, and to promote the rapid and knowledgeable development of product design.

\section{REFERENCES}

[1] He B, Feng P. Research on collaborative conceptual design based on distributed knowledge resource[J]. The International Journal of Advanced Manufacturing Technology, 2013, 66(5):645-662.

[2] Jiaqing Yu, Jianzhong Cha, Yiping Lu. Design synthesis approach based on process decomposition to design reuse[J]. Journal of Engineering Design, 2012, 23(23):526-543.

[3] Shu L H, Cheong H. A Natural Language Approach to Biomimetic Design[M]// Biologically Inspired Design. Springer London, 2014:507-519.

[4] Prado R P, Garcia-Galan S, Exposito J, et al. Knowledge Acquisition in Fuzzy-Rule-Based Systems with Particle-Swarm Optimization[J].IEEE Transactions on Fuzzy Systems, 2010, 18(6): 1083-1097.

[5] Wang J, Wu Y P, Liu X N, et al. Knowledge Acquisition Method from Domain Text Based on Theme Logic Model and Artificial Neural Network[J]. Expert Systems with Applications, 2010,37 (1):267-275.

[6] Liu H C, Liu L, Lin Q L, et al. Knowledge acquisition and representation using fuzzy evidential reasoning and dynamic adaptive fuzzy Petri nets.[J]. IEEE Transactions on Cybernetics, 2013, 43(3):1059.

[7] Castellanos V, Albiter A, Hernandez P, et al. Failure Analysis Expert System for Onshore Pipelines. Part - I: Structured Database and Knowledge Acquisition[J]. Expert Systems with Applications, 2011,38(9):11085-11090.

[8] Zhou Yi, Zhang Xiaodong, Guo bo. Product Innovation DesignOriented Network Knowledge Acquisition and Mining[J]. Modern Manufacturing Engineering, 2010(6):20-23.

[9] Chen Youling, Xiao Yingjiao. Research on Key Technology of Tacit Knowledge Acquisition for Product Design[J]. Science \& Technology Progress and Policy,2011, 28(19):121-124.

[10] Silva M D K, Guyot E, Remy S, et al. A product model to capture and reuse ecodesign knowledge[J]. Ifip Advances in Information \& Communication Technology, 2013, 409:220-228.

[11] Eris O, Leifer L J. "Facilitating Product Development Knowledge Acquisition: Interaction Between the Expert and the Team," $[J]$. International Journal of Engineering Education, 2014, 19(1):142-152.

[12] Chen J, Zhao F, Cao H. Knowledge acquisition from generalized experts oriented to product innovation[C]// International Conference on Information Management, Innovation Management and Industrial Engineering. 2013:546-549.

[13] Burstein G, Virgil C. A Kabbalah System Theory of Ontological and Knowledge Engineering for Knowledge Based Systems[J]. International Journal of Advanced Research in Artificial Intelligence, 2013, 2(2).

[14] Jakupović A, Pavlić M, Han Z D. Formalisation method for the text expressed knowledge[J]. Expert Systems with Applications, 2014, 41(11):5308-5322.

[15] Li Zhiqin, Zhao Hongan, Zhao Fengqi,et al. Knowledge Representation of Propellant Formula Design Based on Semantic Network[J]. Chinese Journal of Energetic Materials, 2014, 22(4):542547.

[16] Wang Li, Li Huaiying. Research on Knowledge Representation for Product Design Based on Ontology[J]. Computer Technology and Development, 2014, 24(9):115-119,145.

[17] Hao Jia, Yang Haicheng, Yan Yan, et al. Configurable Knowledge Component Technology Oriented to Product Design Tasks[J]. Computer Integrated Manufacturing Systems,2012,18(4):705-712.

[18] Hao Jia. Study on Product Design Knowledge Management and Reuse Techniques[D]. Beijing:Beijing Institute of Technology,2014. 